\title{
PEMBERIAN SCAFFOLDING BERDASARKAN KESALAHAN BERPIKIR SISWA DALAM MEMECAHKAN MASALAH MATEMATIKA
}

\author{
Anton Prayitno ${ }^{1}$, Rosdiana Kaka ${ }^{2}$, Abdul Hamid ${ }^{3}$ \\ 1,2,3Pendidikan Matematika, Universitas Wisnuwardhana Malang
}

\begin{abstract}
This research was aimed to elaborate on the form of scaffolding given by learners on algebra problem-solving. The approach used is descriptive qualitative. The study conducted in a junior high school in Malang Regency with 25 students and only two students were selected as research subjects to be given scaffolding level 2 . Data collection method begins by requiring learners to solve algebra and next identify the pattern of mistakes or mistakes. Learners who have wrong answers, used as research samples. The results prove the form of scaffolding given the subject. If the subject experiences an error in understanding the problem, the scaffolding is given asking the subject to re-read the problem properly and carefully and give direction questions. However, if the subject has difficulty in making the planning of the settlement, the scaffolding given is giving the subject the opportunity to rearrange the design of the right answer. If the subject experiences an error in carrying out the planning, the scaffolding given is asking the subject to pay attention to the mathematical concept and to be careful in operating algebra.
\end{abstract}

Keywords: Scaffolding; Thinking error; Solving a mathematics problem

\section{PENDAHULUAN}

Hasil Programme for International Student Assessment (PISA) tahun 2015 menunjukkan rerata skor siswa Indonesia pada bidang matematika adalah 397 (OECD, 2016). Indonesia menempati urutan 63 dari 70 negara untuk bidang matematika. Hal ini menunjukkan bahwa, adanya kesulitan yang dihadapi siswa Indonesia dalam mengerjakan soal matematika. Lebih lanjut siswa Indonesia juga lemah dalam hal pengetahuan, bernalar dan aplikasi dalam matematika. Subanji dan Nusantara (2013) menyatakan bahwa kesalahan yang dibuat oleh siswa merupakan cerminan dari kesulitan yang dihadapi siswa dalam menyelesaikan masalah. Oleh karena itu, kesalahan yang dilakukan oleh siswa ketika mengerjakan masalah matematika perlu mendapatkan perhatian. Apabila kesalahan tersebut tidak segera diatasi maka akan berdampak terhadap pemahaman siswa pada konsep matematika berikutnya (Prayitno, Nurjanah, \& Khasanah, 2017). 
Dalam memperbaiki kesalahan yang dilakukan siswa, maka dibutuhkan pengetahuan mengenali sumber kesalahan melalui proses berpikirnya. Ini menunjukkan bahwa berpikir merupakan aktivitas mental yang dilakukan oleh siswa dalam menyelesaikan masalah yang dapat dilihat perilakunya melalui hasil penyelesaian tugas (Prayitno, 2015; Prayitno, Subanji, \& Muksar, 2016). Karena itu, kemampuan berpikir matematis siswa perlu dikembangkan dalam pemecahan masalah matematika yang sangat kompleks di sekolah. Tentunya untuk memecahkan masalah tersebut dibutuhkan dorongan, bantuan dari orang lain atau orang yang lebih tinggi pengetahuannya. Dorongan ataupun bantuan ini dinamakan dengan scaffolding.

Beberapa penelitian terkait dengan pemberian scaffolding telah banyak dikaji oleh beberapa peneliti (Hidayati, 2013; Indahwati, Subanji, \& Sisworo, 2013; Prayitno, Nurjanah, \& Khasanah, 2017). Hasil kajian tersebut mengungkapkan bahwa kemampuan siswa dalam menyelesaikan masalah dapat berkembang dengan baik apabila diberikan scaffolding oleh guru. Pemberian scaffolding kepada siswa tentunya tidak sama antara satu siswa dengan siswa lain, tergantung masalah yang dihadapinya. Lebih lanjut Van de Pol, Volman, dan Beishuizen (2010) menjelaskan bahwa pemberian scaffolding kepada siswa didasarkan pada tingkat pemahaman yang berbeda. Karena itu, seorang guru dalam memberikan scaffolding perlu memperhatikan cara berpikir siswa sehingga mereka dapat memecahkan masalah yang diberikan. Dalam hal ini, pemberian scaffolding tentunya didasarkan pada kesalahan berpikir siswa ketika belajar matematika (Prayitno, Nurjanah, \& Khasanah., 2017).

Untuk dapat menelusuri kesalahan berpikir matematis maka diperlukan pengetahuan tentang cara memotret berpikir siswa. Dalam hasil penelitiannya Prayitno dan Suarniati (2017) menjelaskan bahwa untuk mempelajari keunikan secara mendalam dari proses berpikir dapat menggunakan peta kognitif. Peta kognitif merupakan teknik untuk merepresentasikan bagaimana subjek berpikir tentang masalah atau situasi tertentu, sehingga peneliti dapat bersikap untuk langkah berikutnya (Ackermann, Eden, Cropper, \& Cropper, 2004). Peta kognitif merupakan cara pandang seseorang terhadap subjek, yang secara kualitatif diuraikan oleh konsep yang terhubung untuk dapat memprediksi perilaku sebab akibat. Oleh karena itu, proses pemberian scaffolding untuk memperbaiki kesalahan berpikir siswa dapat ditelusuri dengan menggunakan peta kognitif. 
Slavin (1997) mendefenisikan bahwa scaffolding merupakan dorongan yang diberikan oleh seseorang yang memiliki pengetahuan lebih. Dalam hal ini, scaffolding merupakan upaya guru atau pengajar yang memiliki pengetahuan lebih tinggi untuk mendorong siswa dalam menuntaskan masalah yang dihadapinya. Lebih lanjut Van Der Stuyf (2002) mendefinisikan scaffolding sebagai gagasan yang digunakan guru, orang tua, atau teman sebaya untuk membantu siswa dalam mengatasi kesulitan atau kesalahan yang dialaminya. Pemberian scaffolding kepada siswa bersifat temporer. Apabila siswa telah mengalami perkembangan, maka secara perlahan-lahan scaffolding akan dikurangi seiring dengan peningkatan kemampuan siswa. Prayitno et al. (2017) dan Van de Pol, Volman, \& Beishuizen (2010) menyatakan bahwa scaffolding bersifat temporer pada siswa agar mereka menjadi mandiri, mengatur diri, dan menjadi problem solver sehingga nantinya dapat menyelesaikan tugas secara mandiri. Dengan demikian, pemberian scaffolding hanya diberikan kepada siswa yang mengalami kesalahan atau kesulitan dalam menyelesaikan masalah matematika.

Berdasarkan hasil observasi diperoleh bahwa kemampuan siswa dalam menyelesaikan soal operasi bentuk aljabar masih tergolong rendah. Hal tersebut ditunjukan dengan kesalahan-kesalahan siswa yang dilakukan siswa saat mengerjakan soal tersebut. Adapun kesalahan yang dialami siswa itu diantaranya: 1) kesalahan dalam memahami soal; 2) kesalahan dalam menentukan teknik penyelesaian; dan 3) kesalahan dalam menyelesaikan masalah sesuai dengan teknik yang direncanakan. Alternatif yang dapat digunakan untuk meminimalisir kesalahan yang dilakukan siswa adalah dengan pemberian scaffolding.

Anghileri (2006) mengungkap adanya pelevelan interaksi dalam pemberian scaffolding, yaitu level 1, level 2, dan level 3. Pada level 1 dikenal dengan environmental provision. Pada level ini, guru perlu mengondisikan lingkungan belajar yang mendukung kegiatan belajar siswa (classroom organization), guru membentuk kelompok (peer collaboration), mengatur tempat duduk, menyediakan lembar tugas secara terstruktur, dan menyediakan media. Ini merupakan tingkat paling dasar dalam scaffolding. Pada level 2, terdapat sosialisasi langsung antara pengajar dengan peserta didik. Bentuk sosialisasinya antara lain: 1) menjelaskan (explaning), cara pengajar untuk menyampaikan teori yang dipelajari; 2) meninjau (reviewing), mengenali bagian yang sangat penting berhubungan secara implisit konsep matematika maupun soal yang 
hendak diselesaikan; dan 3) restrukturasi (restructuring), menyederhanakan objek yang terwujud agar diterima oleh peserta didik. Selanjutnya pada level 3 dikenal dengan developing conceptual thingking. Pada level 3, pengajar membimbing peserta didik untuk meningkatkan daya pikir secara konseptual.

Dalam menyelesaikan masalah matematika yang kompleks, siswa mungkin tidak dapat mengidentifikasi informasi/unsur yang diketahui/ditanyakan dari masalah yang diberikan. Dengan adanya hal ini, maka guru perlu membantu siswa untuk memberikan penjelasan, peninjauan kembali, atau penguatan kepada siswa sehingga siswa dapat mencapai pemahaman, yang akibatnya dapat menyelesaikan masalah tersebut (Prayitno et al., 2017) . Oleh karena itu, penelitian ini hanya bisa memakai scaffolding level 2 dari 3 level yang ditemukan Anghileri (2006) termasuk dalam tahapan scaffolding yang disebut fading. Pada tahap fading ini, scaffolding secara berangsur-angsur akan dihentikan ketika siswa dapat sepenuhnya menyelesaikan tugas dengan mandiri.

Quintana et al (2004) menyatakan bahwa terdapat tiga hal yang perlu diperhatikan dalam memberikan scaffolding, yaitu sebaiknya tugas yang diberikan kepada siswa harus berada dalam ZPD siswa, memberikan alternatif penyelesaian untuk mengantisipasi kesalahan yang mungkin ditemukan siswa, dan menyiapkan scaffolding yang sesuai dengan kesalahan tersebut. Karena itu, scaffolding memerlukan kesesuaian antara masalah yang diberikan kepada siswa dengan bantuan yang disediakan oleh guru, sehingga siswa dapat segera memproses informasi secara efektif. Apabila siswa mengalami kesalahan dalam menyelesaikan masalah, maka proses scaffolding yang diberikan guru adalah meminta siswa lebih teliti membaca masalah tersebut. Guru dapat menganjurkan kepada siswa untuk meminta mencari informasi apa saja yang terdapat dalam masalah tersebut. Misalnya, guru meminta siswa untuk menunjukkan unsur apa saja yang diketahui dan yang ditanyakan pada masalah tersebut. Informasi inilah yang nantinya bisa dijadikan bekal oleh siswa untuk menentukan metode penyelesaiannya. Oleh karena itu, maka tujuan dari penelitian ini adalah mendeskripsikan pemberian scaffolding berdasarkan kesalahan siswa dalam menyelesaikan masalah matematika.

\section{METODE PENELITIAN}

Penelitian ini menggunakan pendekatan deskriptif kualitatif. Penelitian ini mendeskripsikan bentuk scaffolding ketika siswa melakukan kesalahan dalam 
menyelesaikan masalah matematika khususnya materi tentang aljabar. Siswa yang terlibat dalam penelitian ini adalah 25 siswa kelas VIII di salah satu SMP di Kabupaten Malang, Jawa Timur. Akan tetapi, yang dipilih sebagai subjek hanya 2 siswa. Hal ini didasarkan pada letak kesalahan yang mempunyai karakteristik sama dan dapat di berikan scaffolding level 2. Proses pengumpulan data diawali dengan memberikan instrumen penelitian kepada siswa, dan meminta siswa menyelesaikan secara mandiri. Siswa yang menjawab dengan benar tidak dijadikan sebagai subjek penelitian. Sedangkan siswa yang belum menjawab dengan benar dipertimbangkan untuk dipilih sebagai subjek penelitian. Siswa yang dijadikan subjek penelitian, selanjutnya diberikan intervensi sekedarnya agar siswa dapat memperbaiki hasil pekerjaannya. Proses pemberian scaffolding ini tercermin ketika peneliti memberikan intervensi kepada siswa ketika melakukan refleksi terhadap hasil pekerjaannya. Berikut instrumen penelitian yang diberikan kepada siswa.

Terdapat 3 bilangan yang apabila dijumlahkan hasilnya 96. Bilangan kedua tiga kali dari bilangan yang pertama. Bilangan yang ketiga yaitu empat kali dari bilangan pertama. Bilangan berapa sajakah itu?

Pada penelitian ini, subjek yang dipaparkan hanya 2 subjek dan berikutnya disebut S1 (subjek 1) dan S2 (subjek 2). Siswa yang ditetapkan sebagai subjek penelitian diberikan kesempatan untuk melakukan refleksi terhadap yang telah dikerjakannya. Proses berikutnya, peneliti menanyakan jawaban soal hasil kerjanya. Hal ini digunakan untuk mengetahui kesalahan berpikir siswa dalam menyelesaikan masalah. Data tersebut, selanjutnya dianalisis secara kualitatif berdasarkan analisis tahapan Creswell (2009).

\section{HASIL PENELITIAN DAN PEMBAHASAN}

Deskripsi bentuk scaffolding yang diberikan pada siswa akan dijabarkan berdasarkan kesalahan yang dialami siswa saat mengerjakan lembar tes. Paparan tersebut akan dijelaskan sebelum memberikan scaffolding kepada siswa maupun setelah memberikan scaffolding. Berikut ini akan ditunjukkan hasil pekerjaan masing-masing subjek. Subjek S1 ini, mulai dari memahami masalah. Hasil pekerjaan S1 ditunjukkan pada Gambar 1. 


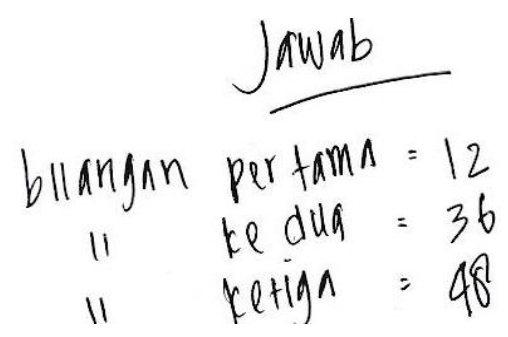

Gambar 1. Kesalahan S1 Sebelum Diberikan Scaffolding

Berdasarkan pekerjaannya pada tes yang diberikan, S1 tidak menuliskan pemisalan terlebih dahulu sebagaimana tampak pada Gambar 1. Hal ini mengakibatkan S1 tidak mengetahui apa yang diketahui dan ditanyakan. Dengan melihat hal tersebut, membuktikan S1 belum mampu memahami masalah. Kesalahan berikutnya, S1 tidak menyelesaikan masalah sesuai dengan langkah-langkah penyelesaiannya.

Berdasarkan hasil pekerjaan S1 di atas, menunjukkan bahwa S1 tidak mampu memahami masalah dan tidak mampu membuat perencanaan penyelesaian. Pada tahap memahami masalah, S1 tidak membuat pemisalan terlebih dahulu sehingga tidak bisa menentukan informasi yang diketahui dan yang menjadi pertanyaan yang akan dicari dalam soal. Sementara pada tahap membuat perencanaan, S1 tidak menyelesaikan masalah sesuai dengan langkah-langkah penyelesaiannya. Hal ini mengakibatkan S1 tidak mampu menuliskan model matematika sesuai dengan apa yang diketahui dan ditanyakan.

Walaupun hasil akhirnya benar, tetapi ketika siswa belum mampu membuat perencanaan, ini sudah masuk kategori salah. Untuk mengatasi kesalahan yang dilakukan S1, maka peneliti perlu memberi bantuan atau scaffolding berupa reviewing, explaining, dan rectructuring yang dijelaskan oleh Anghileri (2006). Bentuk scaffolding yang diberikan kepada S1 pada tahap memahami masalah adalah reviewing yaitu: 1) meminta S1 untuk membaca kembali masalah dengan baik dan teliti; 2) mengajukan pertanyaan arahan sehingga siswa mampu menyebutkan konsep matematika yang sesuai dengan apa yang diketahui. Kemudian dilanjutkan tahap restructuring, dimana melakukan tanya jawab yang mengarahkan siswa agar menemukan apa saja yang diketahui serta ditanyakan dalam soal nomor 1 . Berikut cuplikan wawancara untuk S1:

Peneliti : "Apa saja yang diketahui dalam soal tersebut?"

S1 : "Angka 96 dan angka kedua tiga kali dari angka pertama, angka yang ketiga empat kali dari angka yang pertama"

Peneliti : "apakah angka tersebut sudah diketahui?"

S1 : "belum, masih petunjuk saja."

Peneliti : "oh iya, berarti sudah paham." 
Setelah proses tanya jawab, S1 sudah mengerti masalah yang diberikan dan sudah bisa menuliskan apa yang diketahui dan ditanyakan. Pada tahap membuat rencana penyelesaian, S1 diberikan scaffolding berupa explaining, yaitu memberi kesempatan kepada S1 untuk bernalar dan menyusun kembali rancangan jawaban yang tepat. Dengan pemberian scaffolding terlihat bahwa S1 dapat mengatasi masalah yang diberikan. Hasil pekerjaan S1 yang benar disajikan pada Gambar 2.

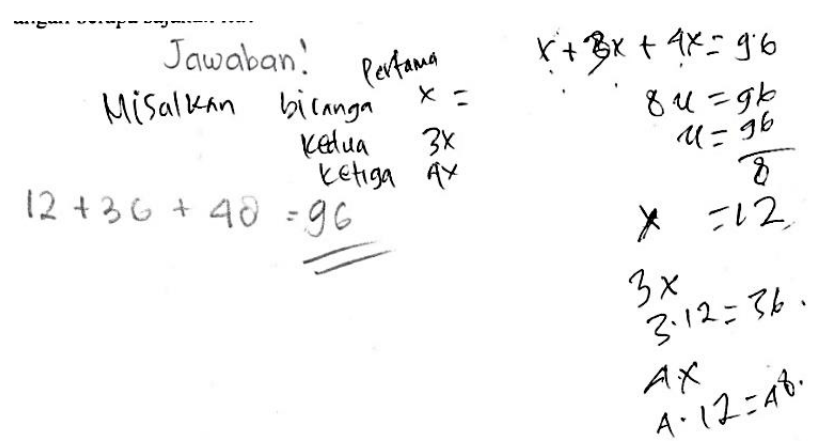

Gambar 2. Hasil Kerja S1 Setelah Diberikan Scaffolding

Struktur berpikir S1 ditinjau dari peta kognitif sebelum dan selama diberikan scaffolding disajikan pada Gambar 3.

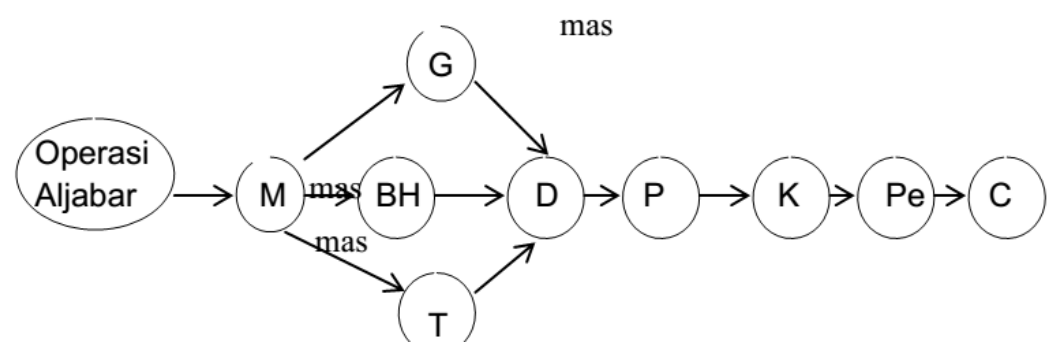

Struktur berpikir sebelum diberikan scaffolding

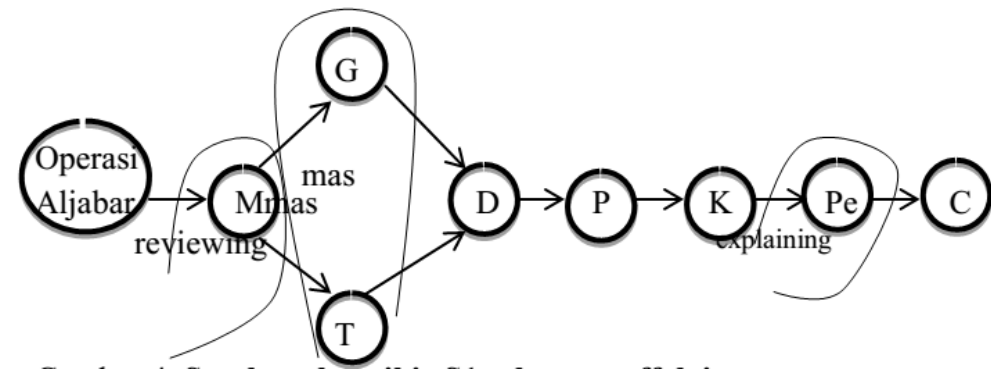

Struktur berpikir selama diberikan scaffolding

Gambar 3. Struktur Berpikir S1 dengan Menggunakan Peta Kognitif

Selama pemberian scaffolding, S1 dapat menyelesaikan masalah yang diberikan dengan benar, dan juga pola berpikir S1 sudah mengalami perubahan dan perkembangan. Hal ini menunjukkan bahwa S1 dapat menyelesaikan masalah dengan 
benar. Perubahan dan perkembangan yang dialami S1 dapat dilihat saat dia sudah bisa memahami masalah dan membuat perencanaan penyelesaian. Sebelum pemberian scaffolding S1 tidak mampu memahami dan membuat perencanaan penyelesaian masalah.

Kesalahan yang dilakukan S2 tidak berbeda jauh dengan kesalahan yang dilakukan oleh S1. Proses berpikir S2 mulai dari memahami masalah. Jawaban S2 sebelum diberikan scaffolding disajikan pada Gambar 4. Dari hasil pekerjaan S2, terlihat bahwa dia belum memahami masalah karena S2 tidak bisa menentukan apa yang diketahui dan ditanyakan secara tertulis dari tes yang diberikan.

Jawaban.

$$
\begin{aligned}
1.42 & +32+22 \\
& =74+22 \quad \text { (Bilangan } 42,32,22 .) \\
& =96
\end{aligned}
$$

Gambar 4. Kesalahan S2 Sebelum Diberikan Scaffolding

Berdasarkan Gambar 4 di atas, S2 mengalami beberapa kesalahan diantaranya adalah salah dalam memahami soal, membuat perencanaan, serta melaksanakan perencanaan penyelesaian. Berdasarkan pekerjaannya, S2 kurang mampu melakukan pemisalan terlebih dulu. Scaffolding yang tepat diberikan untuk S2 pada tahap memahami masalah adalah explaining. Pada tahap ini, S2 diminta untuk fokus memperhatikan soal kemudian soal dibacakan dan diberikan penekanan suara pada kata yang danggap penting berkaitan dengan yang sudah diketahui dan yang akan dicari dalam soal.

Setelah S2 bisa menentukan informasi yang diketahui dan yang akan dicari dalam soal tersebut, scaffolding berikutnya adalah reviewing. Pada tahap ini, S2 diminta untuk membaca ulang soal dan mengungkapkan yang sudah diketahui dan yang dicari dalam soal tersebut agar S2 dapat membuat model matematika. Kesalahan berikutnya yang dilakukan S2 terletak pada tahap perencanaan penyelesaian masalah, dimana S2 tidak menggunakan konsep matematika dengan baik sehingga pada proses penghitungan untuk mencari bilangan pertama, kedua, dan ketiga salah. Untuk mengatasi kesalahan tersebut, diberikan scaffolding berupa explaining. Pada tahap ini, perhatian S2 diarahkan pada soal dengan membaca kembali soal dan memberikan tekanan suara pada 
kata yang dianggap penting yang berkaitan dengan mencari bilangan-bilangan tersebut. Selanjutnya diberikan scaffolding berupa reviewing. S2 diminta untuk membaca ulang serta mengungkapkan apa saja yang telah mereka dapatkan yang berhubungan dengan model matematika. Scaffolding terakhir yang diberikan adalah restructuring. Pada tahap ini lebih mengarah pada kemampuan siswa untuk membuat model matematika dari sebuah soal. Peneliti memberikan pertanyaan, seperti "dari pemisalan tersebut, diapakan lagi?" untuk membantu siswa mengatasi kesalahan dalam membuat model matematika.

Kesalahan yang dilakukan selanjutnya adalah menyelesaikan operasi aljabar dengan penjumlahan untuk mencari bilangan pertama, kedua, dan ketiga. Scaffolding yang diberikan adalah reviewing. Pada tahap ini, S2 diminta teliti dalam mengoperasikan penjumlahan operasi bentuk aljabar. Scaffolding yang diberikan selanjutnya untuk membantu siswa membuat kesimpulan, yaitu memberikan beberapa pertanyaan yang dapat merangsang siswa kepada kesimpulan yang diinginkan. Dengan pemberian scaffolding, S2 dapat menyelesaikan masalah yang diberikan dengan benar. Hasil pekerjaan S2 setelah pemberian scaffolding ditunjukkan pada Gambar 5.

$$
\begin{aligned}
& \text { Misal bilangan pertama dilambangkan dgn } u \\
& \begin{array}{lll} 
& \text { kedua " vetiga " } & 3 u \\
&
\end{array} \\
& x+3 v+4 x=96 \\
& 8 x=96 \\
& v=\frac{96}{8} \\
& x=12 \\
& 3 \cdot x t=3 \cdot 12 \\
& \begin{aligned}
& =36 \\
4 v & =4.12
\end{aligned} \\
& \begin{aligned}
&=48 \\
& \text { Jadi bilongan Pertama 12, bilangan } \\
& \text { pecelua } 36 \text {, dan bilangan ketiga } 48
\end{aligned}
\end{aligned}
$$

Gambar 5. Hasil Kerja S2 setelah Pemberian Scaffolding

Struktur berpikir S2 ditinjau dari peta kognitif sebelum dan selama diberikan scaffolding disajikan pada Gambar 6. 


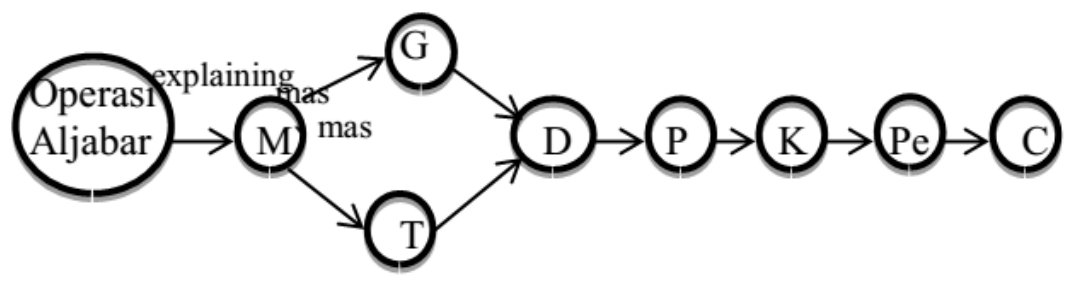

Struktur berpikir S2 sebelum diberikan scaffolding

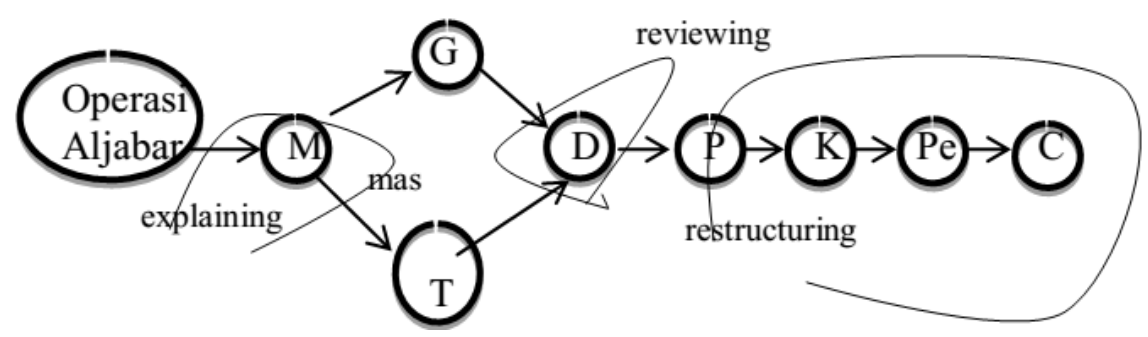

Struktur berpikir S2 selama diberikan scaffolding

Gambar 6. Struktur Berpikir S2 dengan Menggunakan Peta Kognitif

Berdasarkan struktur berpikirnya, S2 mengalami perkembangan dalam mengerjakan soal yang diberikan. Hal ini menunjukkan adanya perbedaan S2 saat mengerjakan soal sebelum pemberian scaffolding dan sesudah pemberian scaffolding, yaitu sebelum pemberian scaffolding S2 tidak mampu menyelesaikan soal yang diberikan dengan benar, tetapi setelah pemberian scaffolding S2 sudah dapat menyelesaikan soal yang diberikan dengan benar. Dalam hal ini, ilustrasi berpikir siswa sebelum scaffolding dan sesudah scaffolding dapat berbeda pula.

\section{SIMPULAN DAN SARAN}

Bentuk scaffolding yang diberikan subjek pada tahap memahami tahap masalah (understanding the problem), yaitu subjek diminta membaca ulang masalah dengan baik dan teliti. Selanjutnya, memberikan pertanyaan arahan kepada subjek agar subjek memahami masalah. Sedangkan pada tahap membuat perencanaan penyelesaian masalah (devising a plan), bentuk scaffolding yang diberikan pada subjek adalah memberikan kesempatan pada subjek untuk bernalar dan menyusun kembali rancangan jawaban yang tepat. Pada tahap melaksanakan perencanaan (carrying out the plan), bentuk scaffolding yang diberikan yaitu meminta subjek untuk memperhatikan konsep aljabar dan teliti dalam mengoperasikan penjumlahan operasi bentuk aljabar, kemudian diberikan scaffolding untuk membantu siswa membuat kesimpulan dengan memberikan beberapa pertanyaan yang dapat merangsang siswa kepada kesimpulan yang diinginkan. 
Saran yang bisa disampaikan untuk penelitian lanjutan adalah memberikan batasan scaffolding yang diberikan oleh guru kepada siswa dalam membantu memecahkan masalah matematika yang dihadapi dan pencarian kesalahan siswa terhadap masalah matematika yang lain.

\section{DAFTAR RUJUKAN}

Ackermann, F., Eden, C., Cropper, S., \& Cropper, S. (2004). Getting Started with Cognitive Mapping. In The 7th Young OR Conference (pp. 1-14). The University of Warwick.

Anghileri, J. (2006). Scaffolding practices that enhance mathematics learning. Journal of Mathematics Teacher Education, 9(1), 33-52. https://doi.org/10.1007/s10857006-9005-9

Creswell, J. W. (2009). Research Design Qualitative, Quantitative, and Mixed Approaches (3rd ed). United Kingdom: SAGE.

Hidayati, N. R. (2013). Proses Berpikir Siswa dalam Memecahkan Masalah Program Linier dengan Pemberian Scaffolding. Tesis Tidak Dipublikasikan. Universitas Negeri Malang.

Indahwati, P., Subanji, \& Sisworo. (2013). Proses Berpikir Siswa Kelas VIII SMPN 2 Blitar Dalam Pemecahan Masalah Himpunan Dengan Pemberian Scaffolding. In Konferensi Nasional Pendidikan Matematika (KNPM) V (pp. 367-375). Malang: UM.

OECD. (2016). PISA 2015 Results (Volume I): Excellence and Equity in Education. Paris: OECD Publishing. https://doi.org/http://dx.doi.org/10.1787/9789264266490-en

Prayitno, A. (2015). Proses Berpikir Refraktif Mahasiswa dalam Menyelesaikan Masalah Matematika. Disertasi Tidak Dipublikasikan. Universitas Negeri Malang.

Prayitno, A., Subanji, \& Muksar, M. (2016). Refractive Thinking with Dual Strategy in Solving Mathematics Problem. IOSR Journal of Research \& Method in Education Ver. III, 6(3), 49-56. https://doi.org/10.9790/7388-0603034956

Prayitno, A., Nurjanah, E. F., \& Khasanah, F. (2017). Characterization of Scaffolding Based on The Students' Thinking Error In Solving Mathematic Problem. Jurnal Kependidikan, 1(1), 50-66.

Prayitno, A., \& Suarniati, N. W. (2017). Construction Students' Thinking in Solving Mathematics Problem Using Cognitive Map. Global Journal of Pure and Applied Mathematics, 13(6), 2735-2747. 
Quintana, C. et al. (2004). A Scaffolding Design Framework for Software to Support Science Inquiry. Journal of the Learning Sciences, 13(3), 337-386. https://doi.org/10.1207/s15327809j1s1303_4

Slavin, R. E. (1997). Educational psychology: Theory and practice. New York: Allyn Bacon Inc.

Subanji, \& Nusantara, T. (2013). Karakterisasi Kesalahan Berpikir Siswa Dalam Mengonstruksi Konsep Matematika. Jurnal Ilmu Pendidikan, 19(2), 208-217. https://doi.org/http://dx.doi.org/10.17977/jip.v19i2.4215

Van de Pol, J., Volman, M., \& Beishuizen, J. (2010). Scaffolding in Teacher-Student Interaction: A Decade of Research. Educational Psychology Review, 22(3), 271296. https://doi.org/10.1007/s10648-010-9127-6

Van der Stuyf, R. R. (2002). Scaffolding as a Teaching Strategy. Retrieved from workplacesafety.pbworks.com/f/Scaffold Learning.doc 